\title{
QUALIDADE SANITÁRIA DE SURURU (Mytella guyanensis) BENEFICIADO POR COMUNIDADE QUILOMBOLA
}

\author{
FERNANDA FREITAS* \\ MONIQUE LIMA DOS SANTOS** \\ GABRIELY SOBRAL NEIVA** \\ ISABELLA DE MATOS MENDES DA SILVA*** \\ ANA LÚCIA MORENO AMOR**** \\ ROBERVAL DE JESUS ASSUNÇÃO*****
}

\begin{abstract}
O objetivo deste trabalho foi avaliar as condições higiênicosanitárias do processamento de sururu, por meio da caracterização microbiológica, parasitológica e físico-química das etapas do beneficiamento. A análise microbiológica de coliformes totais, Escherichia coli (E. coli) e Staphylococcus aureus (S. aureus), foi realizada por método rápido de contagem por placas Petrifilm ${ }^{\mathrm{TM}} \mathrm{e}$ por método cromogênico, e para avaliação parasitológica, foram utilizados o exame direto e o método de Faust. Para obtenção da qualidade da água, foram avaliados os parâmetros físicoquímicos: condutividade, $\mathrm{pH}$ e turbidez. Os resultados obtidos das mãos das marisqueiras mostraram que $100 \%$ das amostras apresentavam contagem de $S$. aureus $>10^{2}$ UFC/mão e ausência de contaminação por E. coli. Das amostras dos utensílios, $100 \%$ estavam contaminadas com S. aureus, e $11,11 \%$ com E. coli. $\mathrm{Na}$ análise do sururu obtido desconchado pelas marisqueiras, 33,33\% estavam com valores insatisfatórios para S. aureus, e 100\% estavam satisfatórios para E. coli, conforme legislação. Já amostras de sururu obtido em conchas e desconchado em laboratório se encontraram em acordo com os valores recomendados. Referente à qualidade da microbiologia da água, $100 \%$ obteviveram presença de coliformes totais, e $66,66 \%$, de E. coli. Quanto à análise físico-química, $100 \%$ das amostras estavam inadequadas para $\mathrm{pH}$ e adequadas para condutividade e turbidez. Os testes parasitológicos apresentaram resultados negativos para quaisquer tipos e formas de parasitos. Foi possível concluir que a maior fonte de contaminação do sururu foi às mãos das marisqueiras, fazendo-se necessária a realização de atividades formativas, visando a minimizar os riscos de contaminação do sururu e garantindo a saúde do consumidor final.
\end{abstract}

PALAVRAS-CHAVE: CONDIÇÕES HIGIÊNICO-SANITÁRIAS; MOLUSCO BIVALVE; MARISQUEIRAS; PROCESSAMENTO.

\footnotetext{
*Mestre em Nutrição, docente da UFRB, Bahia, BA ('fernandafvn@ufrb.edu.br)

**Graduada em Nutrição, Universidade Federal do Recôncavo da Bahia (UFRB), Bahia, BA

${ }^{* * *}$ Doutora em Medicina Veterinária, docente da UFRB, Bahia, BA.

****Mestre em patologia humana (área: experimental), docente da UFRB, Bahia, BA.

*****Graduado em Química, químico da UFRB, Bahia, BA.
} 


\section{INTRODUÇÃO}

O Mytella guyanensis, popularmente conhecido como sururu, é um molusco bivalve, organismo filtrador que possui a capacidade de absorver toxinas, poluentes químicos e biológicos, inclusive metais tóxicos e micro-organismos presentes na água. A ingestão de moluscos bivalves marinhos, crus ou levemente cozidos, é uma prática que vem aumentando progressivamente em todas as regiões litorâneas do Brasil, devido às riquezas dos recursos naturais do ecossistema aquático (PEREIRA et al., 2007).

A pesca artesanal é uma das principais manifestações da região do Recôncavo da Bahia, um dos berços da cultura baiana. A Baía do Iguape pertence à Baía de Todos os Santos (BTS), situada a cerca de $100 \mathrm{~km}$ a leste de Salvador, cuja principal origem é o rio Paraguaçu e manguezais. Nela, encontram-se 20 comunidades, agrupando cerca de 20.000 pessoas vivendo da pesca artesanal, segundo os agentes do Conselho Pastoral dos Pescadores. Uma delas é a comunidade quilombola Santiago do Iguape, pertencente ao município de Cachoeira, localizada na margem esquerda da Baía do Iguape, no estado da Bahia (PROST, 2010).

As comunidades quilombolas são remanescentes de quilombos que se constituíram a partir de uma grande diversidade de processos, que incluem as fugas com ocupação de terras livres e geralmente isoladas, mas também as heranças, doações e recebimento de terras como pagamento de serviços prestados ao Estado. Além disso, diante da condição de escravidão, desenvolveram formas particulares de organização social. Essas comunidades geralmente se localizam em várias regiões do País, principalmente nas áreas rurais, apresentando relativo grau de isolamento geográfico e vivendo desigualdades sociais e de saúde (BARTH, 1976; SILVA et al., 2008).

Segundo Nishida, Nordi e Alves (2003), as áreas dos manguezais são de extrema importância para as populações ribeirinhas, sendo altamente produtivas e economicamente importantes. Por meio da extração de peixes e mariscos, a população pode adquirir boa parte das proteínas e minerais, tendo assim o consumo de pescado como alternativa de alimentação saudável, por seu valor proteico e baixo conteúdo de gordura.

Apesar do elevado valor nutricional do sururu, a maioria das incidências de surtos associados ao consumo desses moluscos tem sido reproduzida no mundo, especialmente por serem consumidos crus (VIEIRA, 2004; LEAL, 2008; CORTES; WASSERMAN; AVELAR, 2009). Desse modo, são vistos como alimento de alto risco, estando amplamente associados a casos de intoxicação e infecção alimentar, ocasionados, na maioria das vezes, por um cozimento insuficiente do alimento ou por contaminação cruzada, sendo uma possível consequência do aumento da poluição ambiental (PEREIRA et al., 2006; FREITAS et al., 2006).

Para impedir que a carne desconchada do sururu não seja contaminada, é fundamental o controle da higiene dos manipuladores, da limpeza das conchas, dos equipamentos e utensílios durante todo o processamento. (SILVA JUNIOR, 2012). Considerando a carência de estudos relacionados ao processamento artesanal de sururu e suas condições higiênico-sanitárias, 0 presente trabalho teve como finalidade avaliar a qualidade sanitária do processamento de sururu nas comunidades quilombolas no setor norte da Baía do Iguape (BA).

\section{MATERIAL E MÉTODOS}

O estudo foi realizado em quatro comunidades da Baía do Iguape, no mês de junho de 2012, sendo as amostras coletadas no local do beneficiamento do sururu.

O processamento do sururu foi iniciado com a lavagem das conchas, as quais em seguida foram submetidas à pré-cocção, sendo aquecidas até a abertura das valvas. Logo após, a carne do sururu foi separada da concha com o auxílio de objetos perfurocortantes (facas), embalada em saco plástico de primeiro uso e congelada até o momento da comercialização. 
Para determinar a qualidade sanitária do processamento do sururu e a identificação das possíveis fontes de contaminação do produto, foram coletadas amostras das superfícies de contato do marisco em concha, do marisco desconchado sem lavar e lavado, das mãos das marisqueiras e da água das comunidades da região, totalizando 30 amostras.

A avaliação da qualidade microbiológica foi realizada utilizando o método rápido de contagem por placas Petrifilm ${ }^{\mathrm{TM}}$ (3M Company). Para quantificação de coliformes totais, Escherichia coli (AOAC 998.08) e Staphylococcus aureus (AOAC 2003.11), método cromogênico (Readcult $($ ) usado para análise de coliformes totais e termotolerantes em água, e para avaliação parasitológica, foram utilizados o exame direto e o método de Faust (FAUST et al., 1939). Os ensaios foram realizados nos Laboratórios de Microbiologia e Parasitologia do Centro de Ciências da Saúde da Universidade Federal do Recôncavo da Bahia - UFRB.

\subsection{ANÁLISE MICROBIOLÓGICA DOS UTENSÍLIOS, DAS MÃOS DAS MANIPULADORAS E DO SURURU}

Para coleta das amostras dos utensílios e das mãos das manipuladoras, foi utilizada a técnica do esfregaço com swabs estéreis, que foram umedecidos em solução salina a $0,9 \%$ de $\mathrm{NaCl}$ e passado com leve pressão em toda a superfície de contato. Nas mãos das manipuladoras, foram realizados movimentos giratórios na palma da mão até a extremidade dos dedos, na região interdigital, ungueal e dorso da mão, sendo coletada a amostra da mão mais utilizada pela manipuladora, a qual foi previamente lavada. Após esse procedimento, as amostras foram acondicionadas, individualmente, em tubos, identificadas e mantidas sob refrigeração até o momento da análise.

Cerca de $100 \mathrm{~g}$ de cada amostra do sururu foram coletadas assepticamente, com o uso de luvas e máscaras descartáveis. As amostras foram acondicionadas em sacos de primeiro uso e transportadas em caixas térmicas com gelo químico, e os mariscos in natura, em conchas, foram submetidos ao tratamento por calor úmido à temperatura média de $95{ }^{\circ} \mathrm{C}$ durante 15 minutos, para abertura das valvas. Esse processo de pré-cocção foi realizado de acordo com as boas práticas de higiene no laboratório, com o intuito de fazer um comparativo com os achados do processo de précocção realizado pelas marisqueiras e avaliar sua influência na qualidade microbiológica dos produtos.

\subsection{AVALIAÇÃO MICROBIOLÓGICA E FÍSICO-QUÍMICA DA QUALIDADE DA ÁGUA UTILIZADA NO PROCESSAMENTO}

A análise microbiológica da água foi obtida por meio da contagem de coliformes totais e termotolerantes em $100 \mathrm{~mL}$ de amostra, utilizando o método rápido cromogênico, que foi iniciado transferindo o reagente ao frasco estéril contendo a amostra de água, sendo homogeneizado cuidadosamente em rotação do punho em média 25 vezes e incubado a $35^{\circ} \mathrm{C}$ por 24 horas. Após esse período de incubação, os resultados foram interpretados, considerando amostras azuis esverdeadas positivas para coliformes totais e presença de florescente contaminação por E. coli.Para verificação da qualidade da água, foram avaliados os parâmetros físico-químicos, condutividade, $\mathrm{pH}$ e turbidez. A condutividade avaliou a capacidade da água de conduzir eletricidade por meio da presença de íons na solução, obtida por meio do medidor de condutividade de bancada - mCA-150 - MS TECNOPON. O pH avaliou o teor de acidez da água, sendo utilizado o medidor de $\mathrm{pH} / \mathrm{mV}$ I temp - modelo pHs-3B - PHTEK, e para determinação da turbidez, foi utilizado um turbidímetro de bancada - microprocessado - TB 1000 - MS TECNOPON, que determinou a quantidade de partículas em suspensão da água analisada.

\subsection{ANÁLISE PARASITOLÓGICA}

Foram utilizados aproximadamente $10 \mathrm{~mL}$ da primeira diluição de cada amostra para análise parasitológica. Inicialmente, foi realizado o exame direto. Para tal, uma gota das amostras 
do fundo - o tubo falcon - foi transferida para uma lâmina de vidro, acrescentado-se uma gota do corante lugol, seguida de observação em microscópio óptico. Após essa técnica, as amostras foram submetidas à filtração em membranas de celulose (poros de $3 \mu \mathrm{m}$ ), com auxílio de vácuo, que concentraram em sua superfície as partículas existentes nessa diluição. Posteriormente, as membranas foram lavadas por agitação vigorosa com detergente Tween 80 e deixadas em repouso por três horas. A água resultante da lavagem das membranas foi submetida ao método de centrífugo-flutuação em sulfato de zinco (técnica de Faust adaptada para a pesquisa de parasitos em água), e o material flutuante foi corado com lugol e examinado em microscópio óptico comum, com aumentos de 100 e 400 vezes. As amostras foram realizadas em triplicata, para leitura por microscopia.

\section{RESULTADOS E DISCUSSÃO}

\subsection{ANÁLISE MICROBIOLÓGICA DOS UTENSÍLIOS E DAS MÃOS DAS MANIPULADORAS}

Por meio dos resultados apresentados para mãos das manipuladoras na Tabela 1, observouse que $100 \%$ das amostras de mãos apresentaram $S$. aureus em quantidade suficientemente patogênica considerando a referência de $<10^{2}$ UFC/mão conforme Silva Junior (2012), o que indica ineficácia higiênico-sanitária em todas as comunidades avaliadas. Essa elevada contaminação por $S$. aureus dá-se pela presença de lesões nas mãos dessas manipuladoras, decorrentes do processo de captação e desconchamento do marisco.

Quanto à presença de $E$. coli, que pertence ao grupo dos coliformes termotolerantes, nenhuma das amostras de mãos apresentou contagem superior a $10^{1} \mathrm{UFC} /$ mão para esse microorganismo, a qual indica falha no aspecto higiênico do processamento e contaminação de origem fecal. Segundo Litz et al. (2007), na ausência de padrões legais para contagens microbianas em mãos de manipuladores de alimentos, considera-se nível aceitável de contaminação a contagem inferior a $10^{2} \mathrm{UFC} /$ mão para $E$. coli.

Já os coliformes totais, apesar de não serem bons indicadores de contaminação fecal, estavam presentes na maioria das amostras. Desse modo, é notável que as manipuladoras não utilizavam técnica adequada de higienização das mãos no momento do beneficiamento, necessitando de orientação e informação quanto a sua importância.

Resultados semelhantes foram observados em um estudo realizado na Bahia, o qual analisou a qualidade microbiológica e parasitológica de mãos de manipuladores de duas unidades de alimentação, revelou que das 11 amostras analisadas, $72,73 \%$ continham $S$. aureus, e somente uma amostra apresentou contagem elevada de coliformes totais e coliformes termotolerantes, considerando a referência de no máximo $10^{2}$ UFC/mão (BRANDÃO, 2012). Outro achado importante foi realizado por Andrade, Silva e Brabes (2003), que avaliaram as condições microbiológicas em unidades de alimentação, considerando o limite máximo de $10^{3}$ UFC/mão, apresentando $94,10 \%$ e 100\% para coliformes totais e S. aureus, respectivamente, indicando ineficiência nas técnicas de processamento e nos procedimentos de higienização praticados pelos estabelecimentos.

Para análise dos equipamentos e utensílios de preparação, Silva Junior (2012) recomenda ausência de $S$. aureus e $E$. coli em $50 \mathrm{~cm}^{2}$ da amostra. Dos utensílios utilizados para o processamento do sururu, faca e recipiente, $100 \%$ estavam contaminados por $S$. aureus, e $11,11 \%$ por E. coli (Tabela 1). Silva et al. (2011), ao realizarem uma avaliação microbiológica de equipamentos e utensílios utilizados em laticínios da região de Rio Pomba (MG), todos os laticínios estavam fora dos padrões recomendados, considerando $50 \mathrm{UFC} / \mathrm{cm}^{2}$ para contagem de coliformes totais, coliformes termotolerantes e Staphylococcus sp, considerando este mesmo padrão para os coliformes totais $(33,33 \%)$ dos utensílios que estavam contaminados. 
TABELA 1: ANÁLISE MICROBIOLÓGICA DA SUPERFÍCIE DE CONTATO DOS
UTENSÍLIOS E DAS MÃOS DAS MANIPULADORAS

\begin{tabular}{|c|c|c|c|c|c|}
\hline Comunidade & Amostra & $\begin{array}{l}\text { Código } \\
\text { amostra }\end{array}$ & $\begin{array}{c}\text { Coliformes } \\
\text { totais }\end{array}$ & E. coli & S. aureus \\
\hline \multirow{5}{*}{ A } & Faca 1 & A3 & $1,0 \times 10^{1}$ & $<10$ & $1,0 \times 10^{3}$ \\
\hline & Faca 2 & A6 & $3,0 \times 10^{1}$ & $<10$ & $1,0 \times 10^{3}$ \\
\hline & Mão 1 & A4 & $4,6 \times 10^{2}$ & $<10$ & $1,7 \times 10^{4}$ \\
\hline & Mão 2 & A5 & 0 & $<10$ & $5,9 \times 10^{2}$ \\
\hline & Recipiente & A7 & $1,0 \times 10^{1}$ & $<10$ & $1,8 \times 10^{2}$ \\
\hline \multirow{4}{*}{ B } & Faca & B7 & 0 & $<10$ & $1,1 \times 10^{2}$ \\
\hline & Mão 1 & B2 & $1,0 \times 10^{1}$ & $<10$ & $1,2 \times 10^{3}$ \\
\hline & Mão 2 & B5 & $2,0 \times 10^{1}$ & $<10$ & $1,0 \times 10^{3}$ \\
\hline & Recipiente & B6 & 0 & $<10$ & $1,0 \times 10^{1}$ \\
\hline \multirow{3}{*}{ C } & Faca & $\mathrm{C} 2$ & $2,0 \times 10^{2}$ & $<10$ & $2,1 \times 10^{3}$ \\
\hline & Recipiente & C3 & $4,0 \times 10^{4}$ & $1 \times 10^{2}$ & $4,4 \times 10^{3}$ \\
\hline & Mão & $\mathrm{C} 4$ & $5,0 \times 10^{1}$ & $<10$ & $9,0 \times 10^{3}$ \\
\hline \multirow{3}{*}{ D } & Faca & D2 & $1,0 \times 10^{1}$ & $<10$ & $3,0 \times 10^{1}$ \\
\hline & Mão & D3 & $1,8 \times 10^{2}$ & $<10$ & $1,7 \times 10^{3}$ \\
\hline & Recipiente & D4 & $1,9 \times 10^{3}$ & $<10$ & $1,0 \times 10^{1}$ \\
\hline
\end{tabular}

Os utensílios representam uma fonte de contaminação em potencial, principalmente por entrarem em contato direto com os alimentos e fazerem parte de todo processamento e manipulação do sururu, elevando o risco de contaminação cruzada.Outro aspecto relevante observado foi o desgaste que os utensílios apresentavam com seu uso, dificultando sua higienização. De acordo com a resolução RDC $n^{\circ} 216$, de 15 de setembro de 2004, os utensílios, além de serem de material que não transmitam substâncias tóxicas, odores ou sabores aos alimentos, devem ter também uma manutenção adequada, sempre estar em bom estado de conservação e ser resistentes à corrosão e a repetidas operações de limpeza, ao contrário dos que se encontravam nas comunidades.

\subsection{ANÁLISE MICROBIOLÓGICA DO SURURU}

$\mathrm{Na}$ análise do sururu obtido desconchado pelas marisqueiras, foi possível observar que, das amostras analisadas, 33,33\% estavam com valores insatisfatórios para $S$. aureus, pois, de acordo com a categoria de moluscos bivalves "in natura", resfriados ou congelados, não consumidos crus, presente na RDC $n^{\circ} 12$, de 2 de janeiro de 2001, amostras com valores acima de $10^{3} \mathrm{UFC} / \mathrm{g}$ são consideradas impróprias para consumo. 
O sururu sem lavar foi o que apresentou maiores valores de contaminação por $S$. aureus (Figura 1). Quanto aos valores de E. coli, 100\% das amostras apresentaram $<2,3 \times 10^{2}$ UFC/100 $\mathrm{g}$, que é um valor dentro do limite estabelecido (BRASIL, 2012). A contagem de coliformes totais nas amostras de sururu variou de $1,0 \times 10^{1}$ a $4,9 \times 10^{3} \mathrm{UFC} / \mathrm{g}$ (Figura 2). Segundo Franco e Landgraf (2008), esses micro-organismos indicam falhas higiênico-sanitárias no processamento do alimento.

Já as amostras de sururu obtido em conchas e desconchado em laboratório estavam de acordo com os valores recomendados (BRASIL, 2001, 2012). Fazendo um comparativo com um estudo realizado por Nascimento et al. (2011), o qual também avaliou moluscos adquiridos em conchas e realizou o processo de pré-cocção dentro das boas práticas de higiene, também obteve ausência de $S$. aureus, coliformes totais e $E$. coli, comprovando que o tratamento térmico, quando realizado em condições higiênicas satisfatórias e de forma eficiente, diminui a carga microbiana inicial presente no produto.

Tendo isso em vista, é possível afirmar que a contaminação do sururu por $S$. aureus se deu pelas mãos das manipuladoras durante o processamento do marisco, devido à não utilização de práticas de higiene adequadas e do desconhecimento da probabilidade de serem portadoras assintomáticas de micro-organismos. Foi constatado também que, no momento do beneficiamento, o sururu foi exposto à temperatura ambiente, apresentando variação de temperatura de 26 a $37^{\circ} \mathrm{C}$, o que contribuiu para uma rápida proliferação desses micro-organismos.

Um estudo realizado em Alagoas avaliou a qualidade microbiológica de 40 amostras de moluscos (sururu e massunim). Todas as amostras analisadas estavam contaminadas por coliformes termotolerantes $\left(>10^{2} \mathrm{UFC} / \mathrm{g}\right.$ ) de acordo com a legislação vigente, e $86 \%$ apresentaram presença de E. coli (DELGADO et al., 2002).

O sururu proveniente da comunidade $C$ foi o único a apresentar condições impróprias para consumo e comercialização, por revelar valores acima de $10^{3} \mathrm{UFC} / \mathrm{g}$ para $\mathrm{S}$. aureus, tanto no sururu sem lavar quanto no sururu lavado. Tal contaminação decorreu das mãos das marisqueiras, portadoras assintomáticas de $S$. aureus, bem como pela recontaminação por meio do contato com os utensílios mal-higienizados, levando risco de intoxicação alimentar aos consumidores.

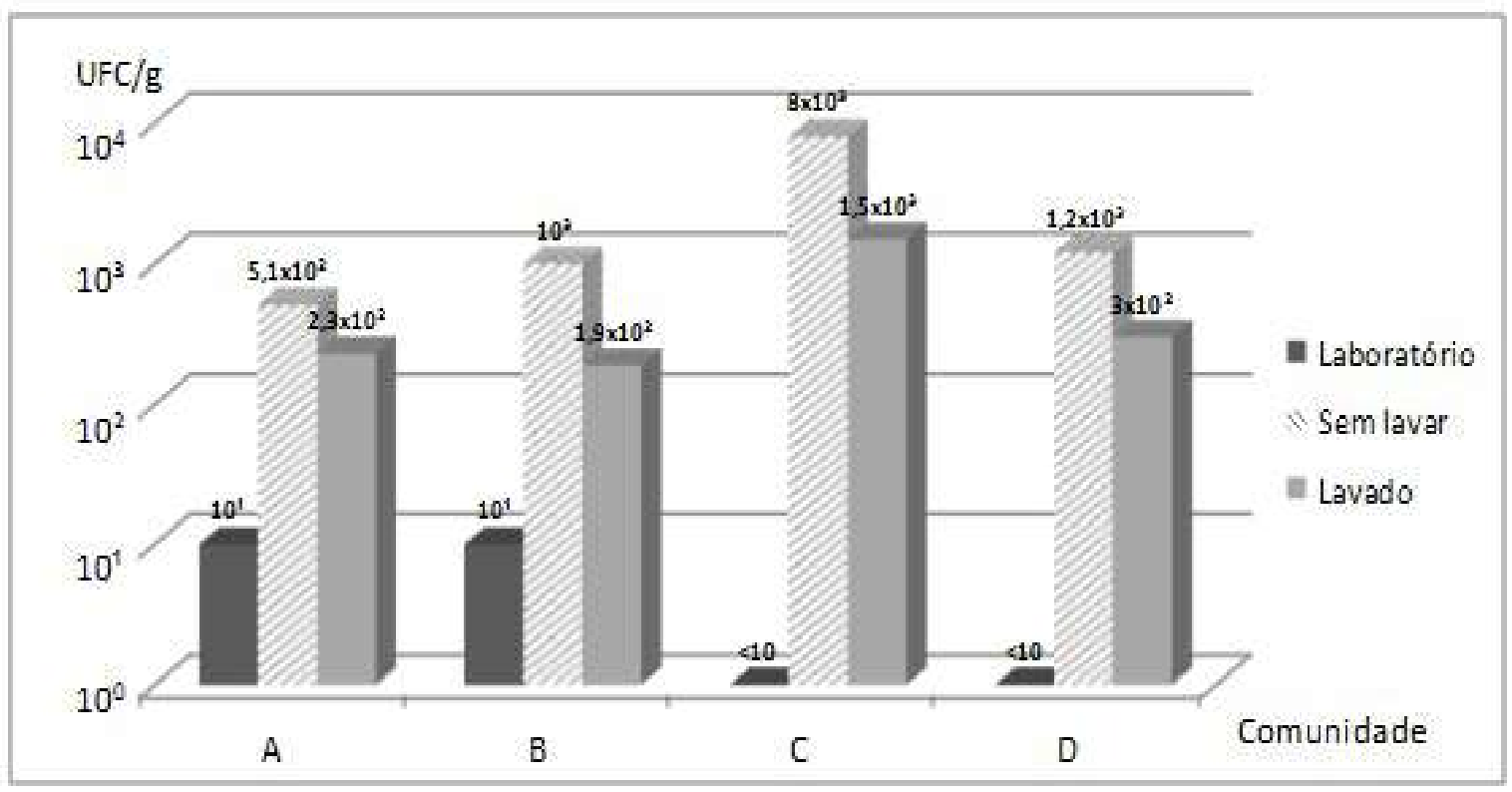

FIGURA 1: DETERMINAÇÃO DE Staphylococcus aureus DO SURURU BENEFICIADO EM DIFERENTES COMUNIDADES (2012) 


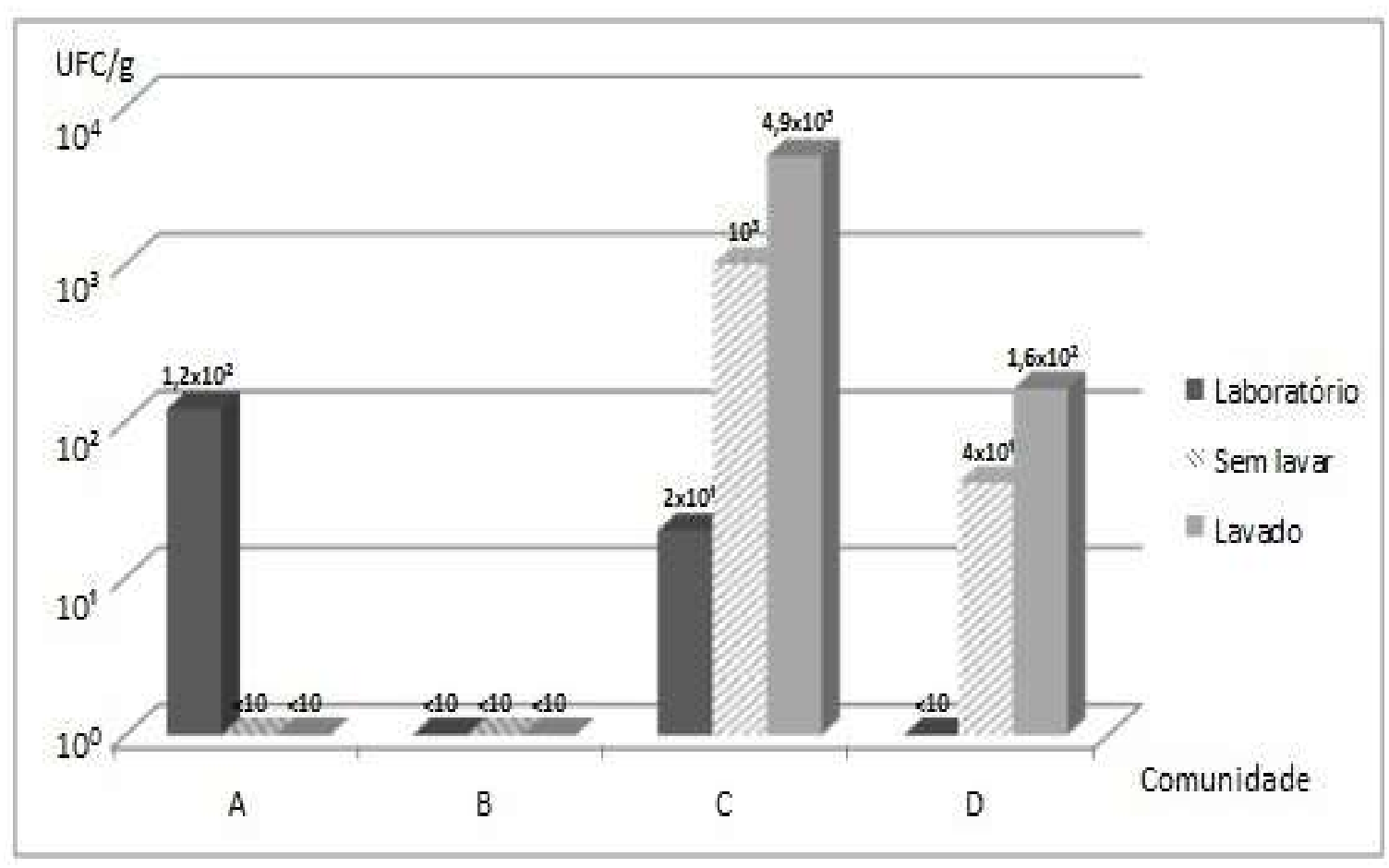

\section{FIGURA 2: DETERMINAÇÃO DE COLIFORMES TOTAIS DO SURURU BENEFICIADO EM DIFERENTES COMUNIDADES (2012)}

\subsection{ANÁLISE DA QUALIDADE DA ÁGUA}

Em relação à qualidade microbiológica das amostras de água, 100\% das amostras analisadas apresentaram presença de coliformes totais, e $66,66 \%$ demonstraram presença de $E$. coli.De acordo com os padrões de potabilidade da água para consumo humano presentes na portaria $n^{\circ} 2.914$, de 12 de dezembro de 2011, a água tratada no sistema de distribuição (reservatórios e rede) deve apresentar, em $100 \mathrm{~mL}$, ausência de $E$. coli e coliformes totais.Apesar da presença de $E$. coli nas amostras de água, não foi possível afirmar que a água das comunidades tenha sido uma fonte de contaminação no processamento do sururu, considerando a diversidade dos métodos microbiológicos utilizados, pois o limite mínimo de detecção do método para amostras de água apresenta maior sensibilidade quando comparado ao método para análise de alimentos. Dessa forma, sugere-se que a quantidade de contaminação da água não foi suficiente para contaminar o sururu.

Casali (2008), ao analisar a qualidade da água para consumo humano ofertada em escolas e comunidades rurais da região central do Rio Grande do Sul, verificou a presença de coliformes totais em $61,8 \%$ das amostras analisadas e $26,5 \%$ de $E$. coli, sugerindo a investigação da origem da fonte de contaminação e a busca das providências imediatas. Outro achado importante foi encontrado por Siqueira et al. (2010), que avaliou microbiologicamente a água de consumo em diferentes unidades de alimentação na cidade do Recife (PE): $62,5 \%$ das amostras analisadas apresentaram coliformes totais, e $42,5 \%$, coliformes termotolerantes, considerando-as impróprias para o consumo humano.

Quanto aos parâmetros físico-químicos da água, foi possível observar que todas as amostras estavam em desacordo com os valores de referência de $\mathrm{pH}$ exigidos por lei que estabelece pH de 6,0 a 9,5 (BRASIL, 2011). Assim, a água utilizada em todas as comunidades se mostrou ácida, uma vez que apresentou valores de 4,54 a 5,38, corroendo equipamentos, neutralizando detergentes alcalinos e dificultando o estabelecimento do $\mathrm{pH}$ ideal nos procedimentos de limpeza (RUZANTE; FONSECA, 2001). Diferente desses resultados, Santos et al. (2012), em estudo realizado no Cruzeiro do Sul (AC), analisaram a qualidade e armazenamento da água utilizada para 
consumo humano e encontrou valores de $\mathrm{pH}$ dentro do recomendando, entre 9,67 e 9,7.Os valores de turbidez apresentaram variação de 0,56 a 3,12, nos quais $100 \%$ das amostras apresentaram conformidade com a lei que estabelece o valor máximo de 5,0 uT como padrão de aceitação para consumo humano (BRASIL, 2011).Ressalta-se que a presença de material em suspensão, referenciada pelos teores de turbidez, reduz a eficiência da desinfecção na inativação dos microorganismos patogênicos, pois nos processos usuais de desinfecção as partículas reagem com os agentes químicos, minimizando a ação do desinfetante (Idem, 2006).

Os valores de condutividade elétrica variaram de 60,38 a 63,84 e estão relacionados com a presença de íons dissolvidos na água, que são partículas carregadas eletricamente, e quanto maior a quantidade de íons dissolvidos, maior a condutividade elétrica na água. Das amostras analisadas, $100 \%$ estavam de acordo com valor permitido, segundo lei que exige de 10 a $100 \mu \mathrm{S} / \mathrm{cm}$ (Ibidem).

\subsection{ANÁLISE PARASITOLÓGICA}

Os testes parasitológicos realizados para todas as amostras analisadas apresentaram resultados negativos para quaisquer tipos e formas de parasitos, mesmo diante da precariedade de saneamento encontrada nas comunidades em estudo. Apesar dos parasitas não se multiplicarem nos alimentos, assim como os vírus, são desencadeadores de doenças provenientes de maus hábitos de higiene e falhas da qualidade sanitária (ASSIS, 2011). O sururu, por ser um molusco bivalve, é capaz de filtrar grandes volumes de água por dia e atuar como indicador biológico de poluição fecal, apresentando patógenos como o Cryptosporidium e Giardia nos locais de cultivo do molusco (LEAL, 2008). Por conseguinte, acredita-se que o ambiente onde o sururu foi capturado não apresenta contaminação de origem parasitológica.

Diferente desses resultados, Cardozo et al. (2012), analisando a correlação entre dados biométricos e parasitológicos de mexilhões (Perna perna) da Ponta do Tinguí, Mangaratiba (RJ), encontraram, nas 100 amostras analisadas, a presença de oocistos de Cryptosporidium, demonstrando contaminação ambiental por fezes humanas ou animais. Embora as comunidades analisadas no atual estudo não exibiram boas condições de saneamento, os indivíduos estudados não apresentaram parasitoses.

\section{CONCLUSÃO}

Diante dos resultados do presente estudo, foi possível o alcance de uma melhor percepção das condições higiênico-sanitárias do beneficiamento do sururu na Baía do Iguape, tendo como maior fonte de contaminação as mãos das marisqueiras, devido a práticas inadequadas de higiene. No entanto, a frequência de produtos impróprios para o consumo apresentou-se baixa, apesar das precárias condições de processamento.

Sendo assim, é notória a necessidade de atividades formativas com as marisqueiras de forma eficaz e permanente, com o objetivo de minimizar os riscos de contaminação do sururu beneficiado, garantindo a saúde do consumidor final.

\section{ABSTRACT}

\section{HEALTH QUALITY OF MUSSELS (Mytella guyanensis) BENEFITED BY A QUILOMBO COMMUNITY}

The aim of this study was to evaluate the hygienic and sanitary conditions of mussels processing, through microbiological, parasitological, and physical-chemical characterization of every processing step. The microbiological analysis of total coliforms, Escherichia coli (E. coli), and Staphylococcus aureus (S. aureus) was performed using a rapid method of Petrifilm ${ }^{\mathrm{TM}}$ plate counting 
and by chromogenic method. To evaluate the parasitological direct examination the Faust method was used. To obtain water quality, physico-chemical parameters were evaluated: conductivity, $\mathrm{pH}$, and turbidity. The results of the hands of the fishers showed that $100 \%$ of the samples had a count of S. aureus $>10^{2} \mathrm{CFU} /$ hand and absence of contamination by E. coli. Of the utensils samples, $100 \%$ were contaminated with $\mathrm{S}$. aureus and $11.11 \%$ with E.coli. In the analysis of mussels with the shell removed by the fishers, $33.33 \%$ presented unsatisfactory values of $S$. aureus and $100 \%$ satisfactory for E.coli, according to the standards set by the Brazilian federal legislation. The samples obtained from mussels in shells and with the shell removed in laboratory, met the recommended values. Water quality microbiology presented $100 \%$ of presence of total coliforms and $66.66 \%$ of E. coli. As for the physical-chemical analysis, $100 \%$ of samples were unsuitable for $\mathrm{pH}$, and had adequate levels of conductivity and turbidity. The parasitological analysis tested negative for any types and forms of parasites. We concluded that the major source of contamination of mussels was at the hands of fishers, making it necessary to perform training activities to minimize the risk of contamination of mussels ensuring the health of the consumer.

KEY WORDS: SANITARY CONDITIONS; BIVALVE MOLLUSK; SEAFOOD FISHER; PROCESSING.

\section{REFERÊNCIAS}

1 ANDRADE, N. J.; SILVA, R. M. M.; BRABES, K. C. S. Avaliação das condições microbiológicas em Unidades de Alimentação e Nutrição. Ciênc. agrotec., Lavras. V.27, n.3, p.590-596, mai/jun. 2003.

2 ASSIS, L. Alimentos seguros: Ferramentas para gestão e controle da produção e distribuição. Rio de Janeiro: Senac Nacional, 2011. 360p.

3 BRANDÃO, I. Qualidade microbiológica e parasitológica de mãos de manipuladores de duas Unidades de Alimentação em um município da Bahia. 2012. 14f. Monografia (Trabalho de conclusão de curso em Nutrição) - Universidade do Recôncavo da Bahia, Santo Antônio de Jesus.

4 BRASIL. ANVISA. Agência Nacional de Vigilância Sanitária. Resolução RDC $n^{\circ} 12$, de 02 de janeiro de 2001. Regulamento Técnico sobre os padrões microbiológicos para alimentos. Jan. 2001.

5 BRASIL. Ministério da Saúde. Agência Nacional de Vigilância Sanitária. RDC n²16, de 15 de setembro de 2004. Dispõe sobre o Regulamento Técnico de Boas Práticas para Serviços de Alimentação. Set. 2004.

6 BRASIL. Ministério da Saúde. Secretaria de Vigilância em Saúde. Vigilância e controle da qualidade da água para consumo humano. Série B. (Textos Básicos de Saúde), Brasília, 212 p. 2006.

7 BRASIL, Ministério da Saúde. Portaria ${ }^{\circ} 2914$, de 12 de dezembro de 2011. Dispõe sobre os procedimentos de controle e de vigilância da qualidade da água para consumo humano e seu padrão de potabilidade. Diário Oficial da União, Brasília, dez. 2011.

8 BRASIL. Ministério da pesca e agricultura. Instrução Normativa interministerial n 7, de 08 de maio de 2012. Institui o Programa Nacional de Controle Higiênico-Sanitário de Moluscos Bivalves (PNCMB), estabelece os procedimentos para a sua execução e dá outras providências. Diário Oficial da União, maio. 2012.

9 CARDOZO, T. S. F.; SANTOS, I. R.; BERTO, B. P.; CARDOZO, S. V.; MESQUITA, E. F. M.; LOPES, C. W. G. Correlação entre dados Biométricos e Parasitológicos de mexilhões (Perna perna) da Ponta do Tinguí, Mangaratiba, RJ. Revista Brasileira de Medicina Veterinária. v. 34, n. 1, p. 9-13, jan/mar 2012.

10 CASALI, C.A. Qualidade da água para consumo humano ofertada em escolas e comunidades rurais da região central do Rio Grande do Sul. 2008. 173f. Dissertação (Mestrado em Ciência do solo) - Programa de Pós-Graduação em Ciência do Solo, Área de Concentração em Processos Químicos e Ciclagem de Elementos, Universidade Federal de Santa Maria, Rio Grande do Sul.

11 CORTES, M.B.V.; WASSERMAN, J.C.; AVELAR, J.C.L. Gestão da Qualidade de Moluscos Bivalves de Cultivos da Baía Da llha Grande (Paraty, Angra Dos Reis e Mangaratiba). In: Congresso Nacional de Excelência em Gestão, 5., 2009, Niterói- RJ. Anais... Niterói: V CNEG, 2009. p.1-12. 
12 DELGADO da SILVA, M. C.; NORMANDE, A. C. L.; FERREIRA, M. V.; RAMALHO, L. S. Avaliação da Qualidade Microbiológica de Pescado Comercializado em Maceió- AL. Higiene Alimentar, São Paulo, v.16, n. 96, p. 61-64. 2002.

13 FAUST, E. C. Comparative efficiency of various technics for the diagnosis of Protozoa and helminths in feces. J. Parasit., 25:241-62, 1939.

14 FRANCO, B. D. G. M; LANDGRAF, M. Microbiologia dos alimentos. São Paulo: Atheneu, 2008.

15 FREITAS, E. I; SANTOS, M. C. S; FARAGE, S; TÓRTORA, J. C. O. Avaliação da Qualidade Microbiológica de Mexilhões Comercializados na Área Urbana de Niterói - RJ. Higiene Alimentar, São Paulo, v. 20, n. 144, p. 101-105. 2006.

16 LEAL, D. A. G. Moluscos bivalves destinados ao consumo humano como vetores de protozoários patogênicos: Metodologias de detecção e normas de controle, Campinas-SP, Brasil. Revista Panamericana de Infectologia. v.10, n. 4, p. 48-57, out/dez. 2008.

17 LITZ, V. M.; RODRIGUES, L. B.; SANTOS, L. R.; PILOTT, F. Anti-sepsia de mãos na indústria de carnes: avaliação da clorhexidina, triclosan e iodóforo na redução da contaminação microbiana em manipuladores. Acta Scientiae Veterinariae, Porto Alegre- RS, v. 35, n. 3, p. 321-326. 2007.

18 NAScimento, V. A.; MitTARAqUiS, A. S. P.; TRAVÁliA, B. M.; SANTOS, R. C. A.; NUNES, M. L.; AQUINO, L. C. L. Qualidade Microbiológica de Moluscos Bivalves - Sururu e Ostras submetidos a tratamento térmico e estocagem congelada. Scientia Plena, Aracaju-Se, v. 7, n. 4, abr. 2011.

19 NISHIDA, A. K.; NORDI, N.; ALVES, R. R. N. Abordagem Etnoecológica da Coleta de Moluscos no Litoral Paraibano. Revista Tropical Oceanography, Recife, v. 32, n. 1, p. 53-68, 2003.

20 PEREIRA, M. A.; NUNES, M. N.; NUERNBERG, L.; DENYS SCHULZ, D.; BATISTA, C. R. V. Microbiological quality of oysters (Crassostrea Gigas) produced and commercialized in the coastal region of Florianópolis Brazil. Journal of Microbiology, São Paulo, v. 37, n. 2, p. 159-163, abr/jun. 2006.

21 PEREIRA, C. S.; POSSAS, C. A.; VIANA, C. M.; RODRIGUES, D. P. Vibrio spp. isolados a partir de mexilhões (Perna perna) in natura e pré-cozidos de Estação Experimental de Cultivo, Rio de Janeiro-RJ, Brasil. Ciência e Tecnologia de Alimentos, Campinas, v. 27, n.2, p. 387-390, abr/jun. 2007.

22 PROST, Cathérine. Resex marinha versus polo naval na baía do Iguape. Novos cadernos NAEA, v. 13, n. 1, p. 47-70, jul. 2010.

23 RUZANTE, J. M.; FONSECA, L. F. L. Água: mais um fator para atingir a qualidade do leite. Revista Batavo. v.8, n.108, p.40-42, 2001.

24 SANTOS, M. I. S.; SOUZA, L. P.; DELGADO, R. C.; SARAH, M. G. M. Análise da qualidade e armazenamento da água utilizada para consumo humano em Cruzeiro do Sul -Acre. Centro Científico Conhecer, Goiânia, v.8, n.14, p. 996, 2012.

25 SILVA JUNIOR, E. A. Manual de Controle Higiênico-Sanitário em Serviços de Alimentação. 6. ed. São Paulo: Varela, 2012.

26 SilvA, D. O.; GUERRERO, A. F. H.; GUERRERO, C. H.; TOLEDO, L. M. A rede de casualidade da insegurança alimentar e nutricional de comunidades quilombolas com a construção da rodovia BR-163, Pará, Brasil. Revista de Nutrição, Campinas, v.21, supl.0, Jul/Ago. 2008.

27 SILVA, N. B. N.; CAHAVES, K. F.; GRAVINA, C. S.; MENDES, A. C. G.; MARTINS, A. D. O.; MARTINS, M. L. Avaliação microbiológica de equipamentos e utensílios utilizados em laticínios da região de Rio Pomba - MG. Rev. Inst. Latic. Cândido Tostes, Santa Terezinha - MG, v. 66, n. 378, p. 5-10, Jan/Fev. 2011.

28 SIQUEIRA, L. P.; SHINOHARA, N. K. S.; LIMA, R. M. T.; PAIVA, J. E.; FILHO, J. L. L.; CARVALHO, I. T. Avaliação microbiológica da água de consumo empregada em unidades de alimentação. Ciênc. saúde coletiva [online], vol.15, n.1, p. 63-66. 2010.

29 VIEIRA, R. H. S. F. Microbiologia, Higiene e Qualidade do Pescado. São Paulo: Varela, 2004, 47p. 